\title{
Prevalence of temporomandibular joint dysfunction in children
}

\author{
Siti Masitoh, Erna Kurnikasari, Rasmi Rikmasari
}

\author{
Department of Prosthodontics Faculty of Dentistry Universitas Padjadjaran
}

\begin{abstract}
The aim of this study is to get the description on TMJ dysfunction as well as its symptoms including clicking, crepitation, jaw opening restriction and muscle pain in children. Thus the result can be used as an input to the program of TMJ dysfunction prevention and treatment for the children in SDN Sirnasari Village, Ciptasari Pamulihan Subdistrict, Sumedang District. This study is descriptive study using survey technique. The samples for the study are 79 children in elementary school taken by random sampling technique with stratification. TMJ dysfunctions with clicking and crepitation symptoms were detected by palpating and using stethoscope. Deviation, deflection, and jaw opening restriction symptoms were found out by visual examination. Whereas pain in TMJ supporting muscles was also detected by palpating. The result of the study shows that the number of children developing TMJ dysfunction with symptom of clicking are 34 children (43.03\%), crepitation are 4 children (5.06\%), deviation are 13 children (16.45\%), deflection are 17 children (21.51\%), jaw opening restriction are 49 children (62.02\%), and pain in TMJ supporting muscles are 69 children $(87.34 \%)$. From the study, it can be concluded that the highest frequency of TMJ dysfunction symptom in SDN Sirnasari children is pain in TMJ supporting muscles. It is followed by jaw opening restriction, clicking, deflection, deviation, and the last is crepitation.
\end{abstract}

Key words: TMJ dysfunction, clicking, crepitation, deviation, deflection, jaw opening restriction, pain in TMJ supporting muscles.

\section{INTRODUCTION}

Temporomandibular joint (TMJ) is the most complex joint. It can open and can be closed as a hinge. It can move forward, backward, and from one side to another side. TMJ plays an important role in mastication, swallowing, and speaking. ${ }^{1,2}$ During mastication process, this joint supports a large number of forces. Excessive force on the joint can cause damage in its structure or alter normal function contact of condyles, disks and eminence. This damage and alteration can result in pain, dysfunction or both. ${ }^{2}$

TMJ dysfunction can occur both in adult and children. One of the factors causing TMJ dysfunction is bad habits in children such as tongue thrust, nail biting, finger sucking, chewing in one side, and bad condition of oral hygiene, which in turn result in posterior teeth premature loss. In children, this kind of dysfunction rarely causes pain, but if it is left without any effort to solve the condition, it can cause further dysfunction. ${ }^{3}$

TMJ dysfunction can affect other joints and muscles around TMJ. The symptoms accompanying 
TMJ dysfunction are clicking, crepitation, asymmetric and restricted mandibular movement, and occasionally pain in jaw, ear, head, face, neck and back. ${ }^{4,5}$

Clicking is the most common symptom of TMJ dysfunction. Studies conducted by some researchers on 6-16 years old children suggest that clicking has higher frequency compared to other symptoms, i.e $35-59.5 \% .^{6}$ This is also supported by the study of Fatimah ${ }^{7}$, suggested that 1107 elementary school students in Bandung City who develop TMJ dysfunction show $55.65 \%$ of clicking symptom.

People living in urban area generally get more health information and services if compared to people living in rural area. This condition affects the health status of the people including oral health, thus the frequency of TMJ dysfunction will likely be high. This is supported by the study of Emmilya. ${ }^{8}$ She conducted a research on the children in Sekolah Dasar Desa Tertinggal Kecamatan Cimalaka, Sumedang District, which show that people awareness in preventing and treating TMJ is still low. It can be seen from the large number of children developing TMJ dysfunction with clicking symptom (33.33\%). We should be concerned to this condition because it can cause worse consequence in the future.

SDN Sirnasari is one of the elementary school in Ciptasari Village, Pamulihan subdistrict, Sumedang District. According to interview result with the principal, this elementary school is still lack of oral health service. Health services such as education and oral examination have never been conducted. This can affect student's health behavior resulting in bad oral health status, thus there are a lot of children develop dental carries and there is no treatment of restoration. This condition can trigger TMJ dysfunction. ${ }^{9}$

Most of the previous studies on children were limited to the discussion of TMJ dysfunction and its clicking symptom. Other symptoms such as crepitation, jaw opening restriction and pain in TMJ supporting muscles need to be studied further. It is because early prevention and treatment on children have important role in the development of TMJ dysfunction.

Based on this background, writer is interested in knowing the description of TMJ dysfunction frequency on the students of SDN
Sirnasari, Sumedang District. It is expected that this study can be a reference in dealing with oral treatment for the community represented by the sample of this study.

\section{METHODS}

The research type is descriptive using survey technique. The research population is 375 children in SDN Sirnasari, Ciptasari Village, Pamulihan Subdistrict, Sumedang District; consist of 187 men and 188 women. The sampling technique is stratified random sampling that form sub-population relative homogen variable and 79 samples are obtained using the following formula.

Tool and material used: Basic tools, dental mirror, explorer, tweezer; stethoscope; caliper; stationery; alcohol $96 \%$ to sterilize the tools; mask and gloves; informed consent form; and examination form.

The research method steps are as follow: (1) The patient is asked to enter the examination room and sit on the chair; (2) The clinical examination of TMJ dysfunction with clicking symptom is performed by placing and palpating the pointy finger $10 \mathrm{~mm}$ in front the ear hole, the smoothness of condyle movement can be felt during the opening and closing mouth. The examination is performed using stethoscope on the lateral of each joint; (3) The clinical examination of TMJ dysfunction with crepitation symptom is performed by placing and palpating the pointy finger on the ear hole, the smoothness of condyle movement can be felt during the opening and closing mouth. Unsmooth sliding and disturbing rough sound of "krek" are supporting the krepitasi symptom. The examination is performed using stethoscope on the lateral of each joints; (4) The clinical examination of TMJ dysfunction with deviation and deflection symptoms during opening mouth is performed by asking the patient to softly open the mouth. Mandible midline displacement on the first opening and return to the midline in the end of the opening are supporting the deviation symptoms during opening the mouth. Whereas the mandible midline displacement from the beginning to the end of opening mouth supports the deflection symptoms during the opening mouth; (5) The clinical examination of TMJ dysfunction with opening mouth restrictiveness symptoms is 
performed by asking the patient to softly open the mouth. If pain or initial clicking sound appeared then measure the inter-initial distance using caliper. After that, patient is asked to maximally open the mouth, then measure the inter-initial distance. The difference between the two interinitial distances supports the mouth opening restrictiveness symptoms; (6) Clinical examination of TMJ dysfunction with supporting muscles pain symptoms is performed using palpation and functional manipulation technique. Initially, the muscle examination is performed by palpating temporal, masseter, sternocleidomastoideus, trapezius, and spenius cavitis muscles. Then continued using functional manipulation to examine inferior, superior and medial lateral pterigoid muscles. The pain and uncomfortable felt by the patient during this treatment support the TMJ supporting muscle pain symptoms.

\section{DISCUSSION}

TMJ dysfunction patients with clicking in SDN Sirnasari (6-13 years old) have frequency of $43.03 \%$. The frequency shows a higher value than elementary school children in Bandung municipality with the same age. ${ }^{7}$ This was resulted because there are differences on behavior and dietary patterns and body posture.

According to Klineberg ${ }^{10}$, the TMJ dysfunction with clicking is caused by neuromuscular disorder on the TMJ supporting muscles as result of excessive muscle work; one of the causes of high caries prevalence. ${ }^{10}$ In this condition, the mastication muscle that is opening and closing mouth muscle is over-contraction resulted in retruded condyle. ${ }^{11}$ Based on the research, the high caries prevalence was founded in SDN Sirnasar children that potentially related to the minimum awareness of the children in the city toward mouth and teeth health maintenance. In contrast, children in the city have a tendency to improve the TMJ dysfunction due to improper restoration, loosing of posterior teeth, and bad behavior such as sucking thumb.

The TMJ dysfunction with clicking is differed into two, unilateral and bilateral clickings, and based on the time it happened, the clicking

Table 1. Prevalence TMJ dysfunction in children at SDN Sirnasari

\begin{tabular}{lcc}
\hline \multicolumn{1}{c}{ Dysfunction } & Total case (n) & Persentage (\%) \\
\hline Clicking Unilateral & 3 & 3.79 \\
$\quad$ Opening & 7 & 8.86 \\
$\quad$ Reciprokal & & \\
Clicking Bilateral $\quad 3$ & 3.75 \\
$\quad$ Opening & 21 & 26.58 \\
$\quad$ Reciprocal & 4 & 5,06 \\
Crepitation & 13 & 16.45 \\
Deviation & 17 & 21.51 \\
Deflection & 49 & 62.02 \\
Restriction of opening mouth & 5 & 6.32 \\
Temporal muscle anterior & 5 & 6.32 \\
Temporal muscle medial & 4 & 5.06 \\
Temporal muscle posterior & 10 & 12.65 \\
Outer masseter muscle & 8 & 10.12 \\
Deep masseter muscle & 17 & 21.52 \\
Pterigoid muscle superior & & \\
Pterigoid muscle inferior & 14 & 17.72 \\
Pterigoid muscle superior & & \\
Sternocleidomastoid muscle & & \\
Cervicalis posterior muscle & & \\
\hline & & \\
\hline
\end{tabular}


symptom can be occur during opening or closing mouth. Table 4.2. shows that the number of SND Sirnasari children who have TMJ with unilateral clicking is 10 children (12.65\%) and 24 children with bilateral clicking (30.38\%). This proves that the bilateral clicking frequency is higher than unilateral clicking. The unilateral clicking is often related to one side-chewing behavior. The bilateral clicking generally happens due to muscle hyperactivity, such as bruxism, sucking thumb, tongue thrust, biting pen or bad occlusion on both side of the jaw. ${ }^{1,13}$

Based on the time it occur, the number of children who have TMJ dysfunction with unilateral opening clicking is 3 children $(3.79 \%)$, and unilateral reciprocal clicking is 7 children $(8.86 \%)$, while children who have bilateral opening clicking is 3 children (3.79\%) and bilateral reciprocal clicking is 21 children (26.58\%). According to this information, the frequency of both TMJ dysfunction with unilateral opening clicking and unilateral reciprocal clicking is similar. On the other hand, the frequency of TMJ dysfunction with bilateral reciprocal clicking symptom is higher than bilateral opening clicking. This shows that muscle imbalance in SDN Sirnasari children is quite higher, because the opening and reciprocal clicking is related to the TMJ dysfunction severity. (1) An excessive muscle imbalance can promotes more severe TMJ dysfunction. In the reciprocal clicking condition, articularis disc has anteromedial displacement causing a loud-thud clicking during opening jaw and soft-thud clicking during closing jaw.

Table shows that the number of SDN Sirnasari children who have TMJ dysfunction with crepitation symptom is relatively small, that is 4 children. Crepitation is one of the TMJ dysfunction symptoms that often disrupts during joint movement. The symptom coincides with pain in TMJ area. Generally, crepitation is caused by degenerative change of TMJ structure. Therfore, such TMJ dysfunction symptom is rarely seen in children.

The result shows that the number of SDN Sirnasari that have TMJ dysfunction with deviation symptom during opening mouth is 13 children (16.45\%) and defection symptom during opening mouth is 17 children (21.51\%), wile TMJ dysfunction patien with opening mouth restriction is 49 children (42.02\%).

The deviation and deflection are symptom often found in TMJ dysfunction patient with clinical sign of mandibular movement midline displacement during opening mouth. This shows a weak condyle movement on one side of jaws.

According to Ogura ${ }^{14}$, the TMJ dysfunction etiologic that often happens in children is oneside chewing, usually due to caries or posterior tooth losing in one side of the jaws that cause uncomfortable feeling on chewing. So only the comfortable side that perform the chewing function. If it is continued then it will lead to TMJ dysfunction. ${ }^{11}$

The mouth opening restriction is a clinical sign where the patient not able to open the mouth maximally. This could happen in TMJ dysfunction with disc displacement without reduction and considered as a chronic TMJ disorder, generally due to TMJ support muscle displacement, such as masseter, and tightened pterigoid lateral because of excessive muscle hyperactivities. This could lead to jaw muscles restriction. If it is not treated, it will become more chronic and severe so the mouth no longer can open (closed lock).

The TMJ dysfunction patients often complain about pain and uncomfortable feeling of TMJ supporting muscle due to unbalancing of muscle work as a result of high caries prevalence, oneside chewing behavior, or body posture deviation.

Table 1. shows a high TMJ dysfunction frequency with TMJ supporting muscle pain that is 69 children $(87.34 \%)$. This was caused of daily behavior of body posture deviation on those children. Bad body postures include wrong sit position during school activities ${ }^{15}$, behavior of carrying bag on one of the shoulder, or bentwalking position on girls who hide her breast that start to grow. If it is continued, it will disrupt the balance of neck muscles, opening and closing mouth muscles, eventually affects the jaw joint.

Based on the entire research it is suggested that the frequency of TMJ dysfunction accompanied by the pain of TMJ supporting muscles is higher than other symptoms (87.34\%), followed by jaw opening restriction (62.02\%), clicking (43.03\%), deflection (21.51\%), deviation (16.45\%), and crepitation (5.06\%).

This result is different from the result of previous study on 6-16 years old children, 
suggested that TMJ dysfunction accompanied by clicking symptom has higher frequency than other symptoms. This is likely due to the difference of zone condition and the number of samples.

The high percentage of pain in TMJ supporting muscles is resulted from unbalanced muscles work caused by children's bad habit such as abnormal oral behavior and abnormal body posture. ${ }^{10}$ Abnormal oral behaviors in children include the habit of finger sucking, bruxism, tongue trust, biting of pencil, chewing by using only one side. ${ }^{1,13}$ Abnormal body postures found in children include wrong posture when the children are studying, playing, walking and other activities. ${ }^{16}$ This abnormal posture will result in strained muscles supporting TMJ. The relevance of mastication muscles with the muscles around the head, neck and back cause the patients of TMJ dysfunction frequently feel pain in facial, head, neck, and back area. ${ }^{5}$

Based on the observation it is found out that children in SDN Sirnasari have minimum knowledge on oral health care. This condition can cause the raise of carries prevalence possibility. Because they do not seek for the treatment/ restoration, the muscles will be more unbalance, and it will affect the condyles. ${ }^{2,4,13}$ Therefore children will undergo other TMJ dysfunction symptoms, including jaw opening restriction, clicking, deflection, deviation and crepitation.

TMJ dysfunction in 6-13 years-old children is categorized as mild dysfunction, because the neuromuscular dysfunction occurred is still in short duration. If this condition is left for a long time, however, unbalancing of the muscles will become severe, thus will affect the condyles. ${ }^{13}$ Hence, early prevention and treatment are so important in order to prevent further TMJ dysfunction.

\section{CONCLUSION}

Based on the research, it can be concluded that the highest frequency of TMJ dysfunction symptoms of the children in SDN Sirnasari, Ciptasari Village, Sumedang District is the pain in TMJ supporting muscles. It is then followed by other symptoms including jaw opening restriction, clicking, deflection, deviation, and the lowest frequency is crepitation.

\section{REFERENCES}

1. Okeson JP. Management of temporomandibular disorders. $2^{\text {nd }}$ ed. St. Louis: Mosby Co.; 1989.

2. Pertes RA, Gross SG. Clinical management of temporomandibular disorders and orofacial pain. Illinois: Quintessence Publishing Co., Inc.; 1995.

3. Himawan H. Pertumbuhan gigi anak harus serius dicermati. Harian terbit. [serial online] [cited 2006 Jan]. Available from: http://www. harianterbit.com.

4. Hollenstein J. Temporomandibular joint (TMJ) syndrome: temporomandibular joint disorders; temporomandibular joint dysfunction; myofascial pain dysfunction syndrome. [cited 2006 Jan]. Available from: http://www.tmj. org.

5. Cooper BC. Temporomandibular Disorders TMJ-TMD and facial pain.[cited 2006 Jan]. Available from: http://www.tmj.org.

6. Bernal M, Tsamtsouris A. Sign and symptoms of temporomandibular joint sound. J Pedodont 1996;10(2):10-3.

7. Patimah TS. Frekuensi disfungsi temporomandibular joint dengan gejala kliking pada anak sekolah dasar negeri di Kotamadya Bandung. Minor thesis. Bandung: Universitas Padjadjaran; 1998.

8. Emmylia G. Frekuensi disfungsi temporomandibular joint dengan gejala kliking pada anak sekolah dasar desa tertinggal di Kecamatan Cimalaka Kabupaten Sumedang. Minor thesis. Bandung: Universitas Padjadjaran; 2001

9. LeResche I. Epidemiology of temporomandibular disorders: Implications for the investigation of etiologic factors. [cited 2006 Aug]. Available from: http://www.iadjournal.org.

10. Klineberg I. Occlusion, Principles and assessment. Wright and Co. Publisher Inc.; 1991.

11. Murphy GJ. Head, neck, oral facial pain and temporomandibular joint disorders. 2006 [cited 2006 Jan]. Available from: http://www. tmjtmd.org.

12. Carlsson GH, Magnusson T. Management of temporomandibular disease in general dental practice. Sweden: Quintessence Publ. Inc.; 1999. 
13. Ogura T. Epidemiologic research about TMJ dysfunction syndrome at teenager. J Clin Pediat Dentist 1990;16(1).

15. Hathaway KM, Parsons E. Behavioural management in patients with temporomandibular disorders. In: Dionne RA. Management of pain and axiety in dental office. Philadelphia: W.B.
Saunders Co.; 2002.

16.Snell R. Anatiomi klinik untuk mahasiswa kedokteran. JAkarta: EGC; 1992.

17.Nelson. IImu Kesehatan Anak. Part III. Jakarta: EGC; 1991.

Ramfjord SP, Ash. Occlusion. $3^{\text {rd }}$ ed. Philadelphia: W.B. Saunders Co.; 1983. 